\title{
Tensile Properties Characterization of Rice Husk Fibre Reinforced Bio-Composite
}

\author{
Kritika Singh Somvanshi*, P.C. Gope**, S. S. Dhami*** \\ *Department of Mechanical Engineering, National institute of Technical Teachers Training and Research, \\ Sector-26, Chandigarh-160019, India. \\ **Department of Mechanical Engineering, College of Technology, G.B. Pant University of Agriculture and \\ Technology, Pantnagar-263145, Uttarakhand, India. \\ *** Department of Mechanical Engineering, National institute of Technical Teachers Training and Research, \\ Sector-26, Chandigarh-160019, India
}

\begin{abstract}
Engineering materials having two or more different physical or chemical properties make composites. In recent years natural fibres from agricultural waste have received more attraction as they offer number of advantages over traditional synthetic fibres. The proposed study has great use of agricultural waste which can be recycled easily and is environmental friendly also. A bio-composite reinforced with rice husk, rice husk particulate and mixture of husk and particulate i.e. hybrid in epoxy resin has been fabricated. The decrease in Ultimate Tensile Strength, Young's Modulus and \% Elongation was observed with increase in wt. \%. Ultimate Tensile Strength, Young's Modulus and \% Elongation was recorded $66.5 \mathrm{MPa}, 616.46 \mathrm{MPa}$ and $10.6 \%$ respectively at $10 \%$ wt of rice husk partic le reinforced composite.
\end{abstract}

Keywords: Rice Husk, particu late, hybrid, rein forced, Epoxy, Tensile Properties .

\section{INTRODUCTION}

Economic use of agricultural by-products are very limited. The good example of this is bagasse, rice husk, sugarcane leafs which are either burned in the field or thrown out. This create sever environmental problems like air pollution, smoke formation and loss of soil moisture. To make efficient use of agricultural by-products, an integrated approach at the level of farmers and industries are required. The aim of this study is reuse of agricultural waste which may be profitable, pollution free and economically viable for the farmers and industries. Among various natural polymers, cellulose natural fibres are envisioned as the most suitable way to solve environmental related issues and increase the income of farmers.

It is estimated that on an average paddy consists of about 20-22 percent husk, 5-8 percentage bran and 70-72 percentage rice. If the husk is burnt, the ash of husk contains the highest proportion of silica. It is also estimated that paddy produces about 0.20 tonnes of husk and every tonne of husk produces about 0.18 to 0.20 tonnes of ash [1]. Rice husk is a by-product of rice milling and around 18.3 million tons of rice husk is produced every year. Rice husk is the agricultural waste which is mostly burned and create pollution problems due to smoke and fine silica ash. The content of silica ash depends on the climatic conditions, variety and geographical location [2].
In present investigation epoxy resin is used as matrix material which has a large industrial applications like adhesives, electronic implements, coating and aerospace structures. They exhibit excellent properties like good adhesion, heat and chemical resistance, electrical and mechanical insulation and low shrinkage on curing [3]. Hardener are chemically active compounds which convert epoxy resin into hard, infusible thermosets and promoted the crosslinking reaction either by poly-addition or by homo-poly merisation [4].

It was seen a negative impact on the tensile strength with increase in fibre content of Rice Husk. It was optimu m for 10wt. \% Rice Husk composite decreased by about $15 \%$ for $40 \mathrm{wt}$. $\%$. The decrease was substantially high compared to pure polypropylene [5]. The tensile strength of bio composite reinforced with only saline treated fibres was more compared to that of composite with untreated fibre [6]. It was observed that addition of rice husk as filler is detrimental to almost all the mechanical properties. About 51\% and 26.8\% decrease in ultimate strength and Young's Modulus for $40 \mathrm{wt}$. \% untreated rice husk reinforcement was observed [7]. 


\section{EXPERIMENTAL DETAILS}

Three different reinforced forms of bio composites using rice husk i.e. particulate form of husk, hybrid (particulate mixed with full rice husk in equal composition) and rice husk as such was used as reinforcement material in the experiment conducted.

\subsection{Materials}

In the present investigation epoxy resin CY-230 has been used as matrix material and HY951, a yellowish-green coloured liquid as hardener to fabricate the rice husk reinforced biocomposites. Rice Husk was purchased from local rice mill for reinforcement in composites at nominal price. However, hardener and matrix was purchased from M/s Excellence Resins Limited, India.

\subsection{Preparation of Mould}

The casting was done in rectangular mould made up of Perspex Sheets of $9 \mathrm{~mm}$ thickness. The dimensions of the mould was $150 \times 120 \times 20 \mathrm{~mm}^{3}$. The casting was an open casting and mixture was directly poured into mould and allowed to settle under gravity for 1 day.

\subsection{Curing}

Rice Husk was washed thoroughly in fresh water to remove dust and dirt. Then dried for whole day in sunlight to remove moisture content. Now $5 \%$ solution of $\mathrm{KOH}$ was made by taking $5 \mathrm{gm}$ $\mathrm{KOH}$ in $100 \mathrm{ml}$ of water. Then according to $5 \%$ solution, Rice Husk was washed and soaked for 30 min. Then cured RH was dried for 2 days in sunlight. After that a part of rice husk was grinded in the form of 425 micron size powder.

\subsection{Casting}

Depending upon the size of the moulds, hardener and epoxy were taken in the ratio 10:1. After that epoxy was put in beakers then husk, particulates and mixture of particulate and husk i.e. hybrid were added to each of them and mixed with mechanical stirrer at $3000 \mathrm{rpm}$. The beakers containing the reinforcement were heated in electric oven for $1 \mathrm{hr}$ at $110^{\circ} \mathrm{C}$ and then allowed to cool down to $45^{\circ} \mathrm{C}$ after which hardener was added. Within the cooling process the moulds were conditioned with silicon grease and M-Seal were applied on corners to stop the matrix flow. The resulting mixture was poured into the mould and allowed to stand till the mixture solidifies. The casting were removed after 2 days .

\subsection{Tensile Testing}

In this study specimens were clamped in the tensile test machine and pulled until failure. During the test, crosshead was moved upward with a constant rate and meanwhile the specimen elongation and applied load was measured. The test was conducted on $25 \mathrm{KN}$ ADMET made servo controlled Universal Testing Machine as shown in Fig 1. The material was tested under displacement control mode at $1 \mathrm{~mm} / \mathrm{min}$ cross-head speed. The tensile tests were conducted on the specimen size $152 \times 20$ $\times 5 \mathrm{~mm}^{3}$ with gauge length of $50 \mathrm{~mm}$ having fillet $24 \mathrm{~mm}$ as shown in Fig 2.

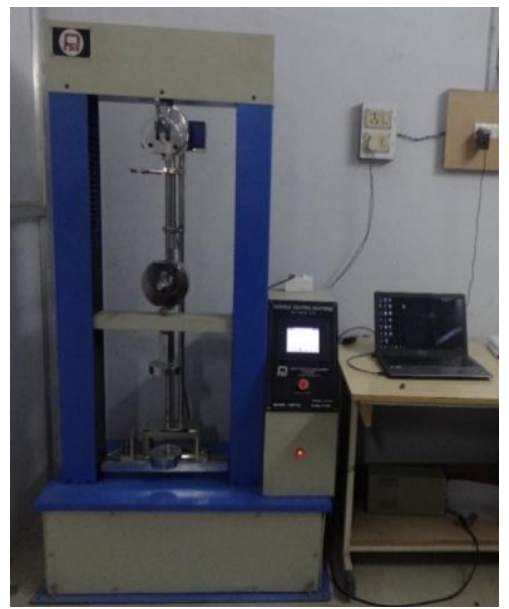

Fig 1. Tensile Testing on UTM

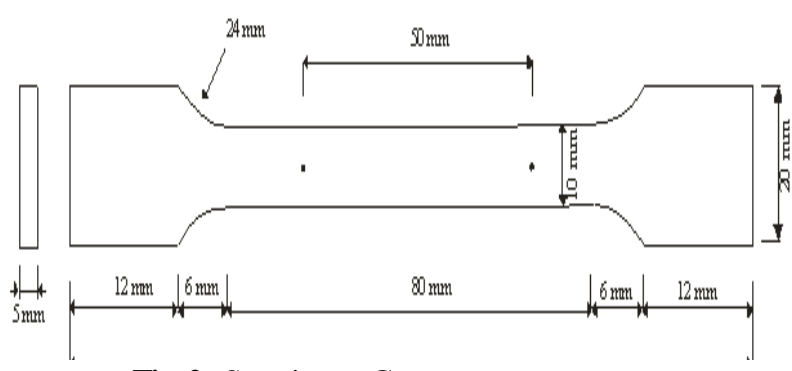

Fig 2. Specimen Geometry

\subsection{Statistical Analysis}

Analysis of variance (ANOVA) is a statistical model that was developed by R.A.Fisher to identify which input parameter (control factor) significantly affects the output. Statistical analys is of the data obtained in the different sets of experiment were calculated by computing the standard error mean (S. Em. \pm ) using following formula

$$
\text { S. Em. } I=\sqrt{\frac{H 5 E}{R}}
$$

Where, MSE = Mean Sum of square due to Error and $\mathrm{R}=\mathrm{Number}$ of replication. The calculation of C.D. at $5 \%$ of table value will be carried out with the help of following formula.

$$
\text { CD. }=\text { S. En. } \pm \sqrt{2 \times \text { TableValue at } 5 \%}
$$

Where, C.D. =Critical Difference and S. Em. = Standard Error Mean 
Kritik a Singh Somvanshi.et.al. Int. Journal of Engineering Research and Application www.ijera.com ISSN : 2248-9622, Vol. 7, Issue 1, ( Part -2) January 2017, pp.01-04

\section{RESULTS AND DISCUSSION}

The results obtained on rice husk mixture of rice husk and its powder and rice husk powder alone as reinforcing material and at different weight percentage i.e. $10 \mathrm{wt}$. $\%, 15 \mathrm{wt} . \%$ and $20 \mathrm{wt}$. $\%$ have been presented and were put to statistical test of significance.

\subsection{Ultimate Tensile Strength}

Data given in Table $\mathbf{1}$ and depicted in Fig $\mathbf{3}$ indicates that there is a 'statistical difference among particulate reinforced, husk reinforced and hybrid reinforced bio composites at different wt. $\%$.

TABLE 1 Effect of reinforcement and wt. \% on Ul timate Tensile Strength

\begin{tabular}{|c|c|c|c|c|}
\hline & Particulate & Hybrid & Husk & Mean \\
\hline $\begin{array}{ll}10 & \text { wt. } \\
\% & \end{array}$ & $66.50 \mathrm{MPa}$ & $\begin{array}{l}61.00 \\
\mathrm{MPa}\end{array}$ & $\begin{array}{l}46.00 \\
\mathrm{MPa}\end{array}$ & $\begin{array}{l}57.83 \\
\mathrm{MPa}\end{array}$ \\
\hline $\begin{array}{ll}15 & \text { wt. } \\
\% & \end{array}$ & $60.30 \mathrm{MPa}$ & $\begin{array}{l}50.50 \\
\mathrm{MPa}\end{array}$ & $\begin{array}{l}43.50 \\
\mathrm{MPa}\end{array}$ & $\begin{array}{l}51.43 \\
\mathrm{MPa}\end{array}$ \\
\hline $\begin{array}{ll}20 & \text { wt. } \\
\% & \end{array}$ & 27.05 MPa & $\begin{array}{l}22.95 \\
\mathrm{MPa}\end{array}$ & $\begin{array}{l}14.05 \\
\mathrm{MPa}\end{array}$ & $\begin{array}{l}21.35 \\
\mathrm{MPa}\end{array}$ \\
\hline Mean & $51.28 \mathrm{MPa}$ & $\begin{array}{l}44.82 \\
\mathrm{MPa}\end{array}$ & $\begin{array}{l}34.52 \\
\mathrm{MPa}\end{array}$ & $\begin{array}{l}43.54 \\
\mathrm{MPa}\end{array}$ \\
\hline
\end{tabular}

$\operatorname{sem}($ wt. $\%)=0.50 ; \mathrm{cd}=1.48$

$\operatorname{sem}($ composition $)=0.50 ; \mathrm{cd}=1.48$

sem $($ composition $\times$ wt. $\%)=0.86 ; \mathrm{cd}=2.57$

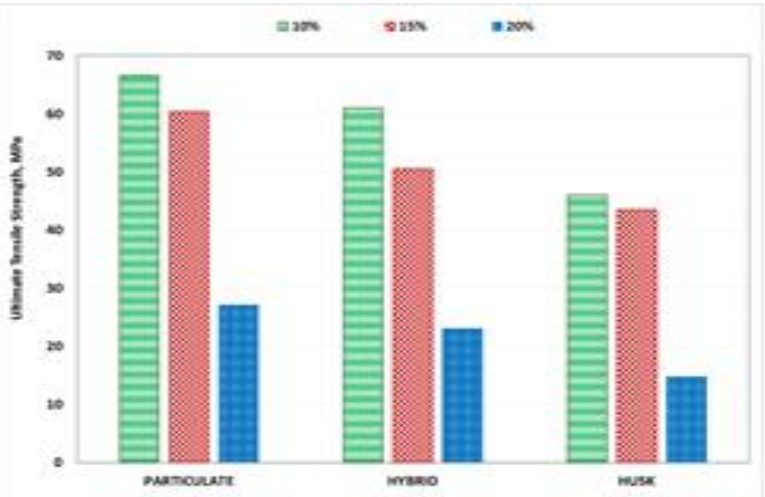

Fig 3 Comparison of Ultimate Tensile Strength

The highest Ultimate Tensile Strength was recorded $66.5 \mathrm{MPa}$ in particulate reinforced at 10 wt. \% followed by $61 \mathrm{MPa}$ and $46 \mathrm{MPa}$ in hybrid reinforced and husk reinforced bio composites respectively. The ultimate tensile strength of particulate, hybrid and husk reinforced bio composite was recorded $60.3 \mathrm{MPa}, 50.5 \mathrm{MPa}$ and $43.5 \mathrm{MPa}$ respectively at $15 \mathrm{wt}$ \%. It was only $27.05 \mathrm{MPa}, 22.95 \mathrm{MPa}$ and $14.65 \mathrm{MPa}$ in particulate, hybrid and husk reinforced bio composite respectively for $20 \mathrm{wt}$. $\%$. The decrease in Ultimate Tensile Strength is due to poor interfacial bonding between hydrophilic fibre and hydrophobic matrix. At 20 wt. $\%$ the fibre to fibre contact inside the bio-composite was more. Because of the poor interfacial bonding effective load transfer could not take place which lead to failure quickly.

\subsection{Young's Modulus}

Data presented in Table 2 and Fig 4 revealed that there is significant difference in Young's Modulus.

TABLE 2 Effect of reinforcement and wt. \% on Young s Modulus Tensile

\begin{tabular}{|c|c|c|c|c|}
\hline & Particulate & Hybrid & Husk & Mean \\
\hline $\begin{array}{ll}10 & \text { wt. } \\
\% & \end{array}$ & $\begin{array}{l}616.46 \\
\mathrm{MPa}\end{array}$ & $\begin{array}{l}587.60 \\
\mathrm{MPa}\end{array}$ & $\begin{array}{l}559.77 \\
\mathrm{MPa}\end{array}$ & $\begin{array}{l}587.94 \\
\mathrm{MPa}\end{array}$ \\
\hline $\begin{array}{l}15 \text { wt. } \\
\%\end{array}$ & $\begin{array}{l}547.46 \\
\mathrm{MPa} \\
\end{array}$ & $\begin{array}{l}472.56 \\
\mathrm{MPa} \\
\end{array}$ & $\begin{array}{l}369.72 \\
\mathrm{MPa} \\
\end{array}$ & $\begin{array}{l}463.24 \\
\mathrm{MPa} \\
\end{array}$ \\
\hline $\begin{array}{ll}20 & \text { wt. } \\
\% & \end{array}$ & $\begin{array}{l}294.51 \\
\mathrm{MPa}\end{array}$ & $\begin{array}{l}292.41 \\
\mathrm{MPa}\end{array}$ & $\begin{array}{l}285.11 \\
\mathrm{MPa}\end{array}$ & $\begin{array}{l}290.67 \\
\mathrm{MPa}\end{array}$ \\
\hline Mean & $\begin{array}{l}486.14 \\
\mathrm{MPa}\end{array}$ & $\begin{array}{l}450.86 \\
\mathrm{MPa}\end{array}$ & $\begin{array}{l}404.87 \\
\mathrm{MPa}\end{array}$ & $\begin{array}{l}447.28 \\
\mathrm{MPa}\end{array}$ \\
\hline
\end{tabular}

$\operatorname{sem}($ wt. $\%)=2.80 ; \operatorname{cd}=8.32$

$\operatorname{sem}($ composition $)=2.80 ; \mathrm{cd}=8.32$

sem $($ composition $\times$ wt. $\%)=4.85 ; \operatorname{cd}=14.42$

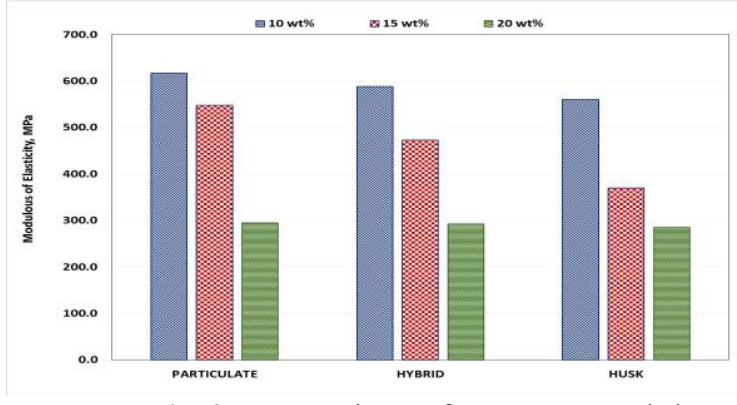

Fig 4. Comparison of Young's Modulus

Young's Modulus was observed 616.46 $\mathrm{MPa}$ in particulate at $10 \mathrm{wt}$ \%. Young's Modulus was recorded $587.6 \mathrm{MPa}$ and $559.77 \mathrm{MPa}$ for hybrid and Husk reinforced bio composite respectively at $10 \mathrm{wt}$. \%.Similarly at $15 \mathrm{wt}$. \% decrease was also observed 547.46 $\mathrm{MPa}, 472.56$ $\mathrm{MPa}$ and $369.72 \mathrm{MPa}$ in particulate, hybrid and Husk reinforced bio composites respectively. At 20 wt. \% the Young's Modulus was found 294.51 $\mathrm{MPa}$ in particulate, $292.41 \mathrm{MPa}$ in hybrid and 285.11 MPa in Husk. The decrease in Young's Modulus of the composites is attributed to the inefficient stress transfer from matrix to fibre because of improper wetting and adhesion between them.

\subsection{Percentage Elong ation}

Effect of wt. \% on elongation at break is given in Table 3 and presented in Fig 5. 
Kritik a Singh Somvanshi.et.al. Int. Journal of Engineering Research and Application www.ijera.com ISSN : 2248-9622, Vol. 7, Issue 1, ( Part -2) January 2017, pp.01-04

TABLE 3 Effect of reinforcement and wt \% on Percentage Elongation

\begin{tabular}{|l|l|l|l|l|}
\hline & Particulate & Hybrid & Husk & Mean \\
\hline 10 wt. \% & $10.60 \%$ & $9.15 \%$ & $7.98 \%$ & $9.24 \%$ \\
\hline 15 wt. \% & $9.48 \%$ & $8.78 \%$ & $5.94 \%$ & $8.07 \%$ \\
\hline 20 wt. \% & $7.99 \%$ & $6.75 \%$ & $4.60 \%$ & $6.45 \%$ \\
\hline Mean & $9.36 \%$ & $8.43 \%$ & $6.17 \%$ & $7.92 \%$ \\
\hline
\end{tabular}

$\operatorname{sem}($ wt. $\%)=0.12 ; \mathrm{cd}=0.37$

$\operatorname{sem}($ composition $)=0.12 ; \quad \mathrm{cd}=0.37$

$\operatorname{sem}(\operatorname{composition} \times$ wt. $\%)=0.22 ; \mathrm{cd}=0.64$

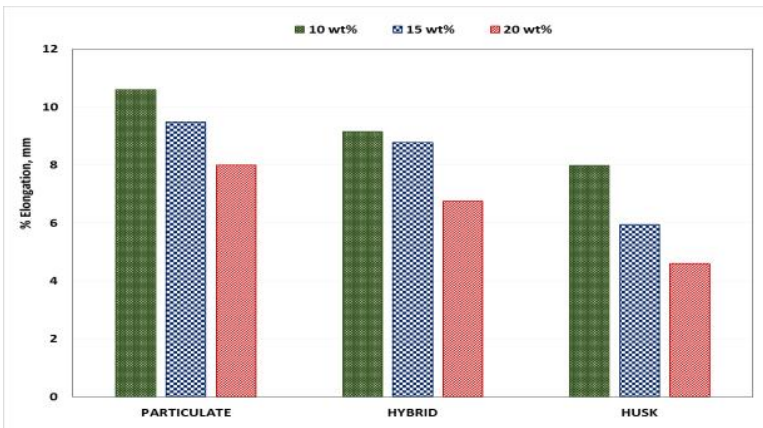

Fig 5. Comparison of \% Elongation

The variation in percentage elongation was found best in particulate i.e. 10.6 at $10 \mathrm{wt}$. $\%$. The percentage elongation in particulate at 15 and 20 wt. \% was recorded 9.48 and 7.99 respectively. Hybrid showed better results i.e. 9.15, 8.78 and 6.75 than Husk which was observed 7.98, 5.94 and 4.6at 10, 15 and 20 wt. \% respectively. Data reveals that addition of fibre results in inducing brittleness into composites. This can be due to the presence of voids which obstructs stress propagation between fibre and matrix.

By performing ANOVA, Standard Error Mean (S. Em.) and Critical Difference (C.D.) at 5\% level of significance was calculated. The values are greater than the S. Em. and C.D. given values which indicates that there is significant difference among different reinforcements at same weight percentage and also for same reinforcement at different weight percentage. Moreover, it also provides a significant difference at interaction of different reinforcement and weight percentage.

\section{CONCLUSION}

From the above results following conclusions can be made:

1. It is attributed that with increase in fibre wt. $\%$ the tensile properties viz. Ultimate Tensile Strength, Young's Modulus and Percentage Elongation decreases.

2. The reduction in tensile properties was due to improper adhesion between hydrophilic fibre and hydrophobic epoxy matrix.
3. It was also statistically proven that $10 \mathrm{wt} \%$ rice husk powder reinforced bio-composite showed best results.

\section{REFERENCES}

[1]. Prasad C. S., Maiti K. N., Venugopal R.,"Effect of RHA in white ware composition”, Ceramics International, Vol.27, 2000, pp. 629-635.

[2]. Panigrahi M. R., Overand R.P., "Proceedings of the third biomass conference of the American", Elsevier Science, Inc., 1997, pp. 79.

[3]. Mauerer O., "New reactive, halogen-free flame retardant system for epoxy resins", Polymer Degradation Stab, 2005, pp. 7073.

[4]. Irfan M.H., "Chemistry and technology of thermosetting polymers in construction application", 2nd edition Boston, Kluwer academic publisher, 1998, pp. 25-28.

[5]. Yang H.S., Kim H.J., Jungil S., Lee H.J.P., Taek S.H., "Rice husk flour filled polypropylene composites mechanical and morphological studies" Composites Structures, 2004, pp. 305-312.

[6]. Kushwaha P.K., Kumar R., "Effect of Silanes on mechanical properties of bamboo fibre epoxy composites", Journal of Reinforced Plastic Composites, 2010, pp. 718-724.

[7]. Bisht N., Gope P.C., "Mechanical properties of rice husk flour reinforced epoxy biocomposite", International Journal of Engineering Research and Applications, Vol. 5, Issue 6, ( Part -3), 2015, pp.123-128. 